\title{
PRODUÇÃO DA FIGUEIRA SUBMETIDA A DIFERENTES ÉPOCAS DE PODA E IRRIGAÇÃO ${ }^{1}$
}

\author{
SARITALEONEL ${ }^{2} \&$ MARCOANTONIOTECCHIO
}

RESUMO - O trabalho teve como objetivo avaliar diferentes épocas de poda, correspondentes aos meses de julho, agosto, setembro e outubro dos anos de 2004/05 e 2005/06, com e sem o uso de irrigação, em figueira 'Roxo de Valinhos', no município de Botucatu-SP. Para atingir tal objetivo, adotou-se o delineamento experimental em parcelas subdivididas, com 5 repetições em blocos, onde as parcelas corresponderam aos tratamentos com e sem irrigação, e as subparcelas foram constituídas pelas podas realizadas nos quatro meses do ano. Foram avaliadas características de produção e alguns atributos de qualidade, que serviram para indicar a necessidade do uso de irrigação. Os resultados obtidos permitiram concluir que, na avaliação do desdobramento da interação entre épocas de poda e irrigação complementar, o mês de agosto, com o uso de irrigação complementar, foi o mais favorável para a realização da poda da figueira, proporcionando as maiores produções médias verificadas no ensaio, tanto no ciclo agrícola de 2004/05 (3.513,8 $\left.\mathrm{g} \mathrm{planta}^{-1}\right)$, quanto em 2005/06 (4.110,7 $\left.\mathrm{g}_{\text {planta }}{ }^{-1}\right)$. Em condições não-irrigadas, não houve diferença estatística entre os meses de julho, agosto e setembro de 2004/05 e entre julho e agosto de 2005/06.

Termos para indexação: Ficus carica L., qualidade de frutos, irrigação, época de poda, produção.

\section{THE YIELD OF FIG TREES AS A FUNCTION OF PRUNING TIME AND IRRIGATION}

ABSTRACT - The research had the purpose to determine the effects of pruning time in July, August, September and October of 2004/ 05 and 2005/06, with and without irrigation, in the fig trees 'Roxo de Valinhos', located in Botucatu/SP/Brazil. The experimental design was in split plots with 5 replications at random in lines, where the plots consisted in the treatments with and without irrigation and the subplots were composed of the pruning accomplished in the four months of the year. It was evaluated the yield and fruits quality. These characteristics could be used to evaluate the irrigation necessity. The August month with irrigation was the best time to the fig trees pruning, enhancing the yield (3.513,8 $\mathrm{g} \mathrm{plant}^{-1}$ in 2004/05 and 4.110,7 $\mathrm{g} \mathrm{planta}^{-1}$ in 2005/06). Without irrigation the pruning made in July, August and September (2004/05) and in July and August (2005/06) was similar.

Index terms: Ficus carica L., fruit quality, irrigation, pruning time, yield.

\section{INTRODUÇÃO}

Dentre as várias espécies frutíferas trazidas ao Brasil pelos italianos, a figueira destaca-se entre as que melhor se adaptaram ao clima subtropical temperado de São Paulo. Atualmente, São Paulo é o segundo produtor nacional de figo, respondendo por todas as exportações brasileiras de figo maduro. Na região de Campinas, principalmente no município de Valinhos, onde a cultura se desenvolveu inicialmente, concentra-se mais de $80 \%$ da produção paulista de figo (ALMEIDA \& DE MARTIN, 1997).

As perspectivas e possibilidades de expansão do cultivo da figueira no Estado de São Paulo são promissoras, principalmente em função de um grande mercado consumidor, além das significativas exportações de figo ao natural as quais entram na entressafra da Turquia, que é o maior produtor mundial, além da produção de figos verdes para industrialização, mercado em expansão no Estado. De acordo com Hernandez et al. (1994), o potencial de produção de figo no interior paulista é expansivo, principalmente em áreas distintas da tradicional região produtora. No entanto, conforme os mesmos autores, fatores culturais, nutricionais e hídricos são de extrema significância no estabelecimento de novas áreas de cultivo. Nesse sentido, o conhecimento do correto manejo do pomar, apropriado à região produtora, bem como aspectos da poda e irrigação figuram como informações relevantes de sucesso, não apenas nos novos campos de cultivo, como também nos já existentes.

Um dos maiores entraves na expansão do cultivo da figueira para o mercado ao natural é a alta perecibilidade da fruta no campo e na pós-colheita, exigindo mercado garantido. Uma das alternativas para aumentar o período de oferta de figos maduros no mercado, é realizar a poda em diferentes épocas do ano. No entanto, a execução e a viabilidade dessa prática estão diretamente relacionadas com as condições climáticas locais.

De acordo com Corrêa \& Santos (1999), na região de Valinhos-SP, a poda é realizada nos meses de julho e agosto, e a colheita dos frutos para mercado estende-se de novembro a maio, concentrando-se entre dezembro e março. Nessa região, a poda em novembro, aliada à irrigação, permite colheita na entressafra, sendo, porém, a produtividade menor. Nas condições do Estado de São Paulo, de maneira geral, as precipitações pluviométricas são suficientes para o desenvolvimento da figueira. No entanto,

${ }^{1}$ (Trabalho 038-08). Recebido em: 08-02-2008. Aceito para publicação em: 29-05-2008. Trabalho financiado pela FAPESP. Processo 03/13766-0 ${ }^{2}$ UNESP. Faculdade de Ciências Agronômicas. Departamento de Produção Vegetal/Horticultura. Caixa Postal 237. CEP - 18610-307. Botucatu-SP. sarinel@fca.unesp.br

${ }^{3}$ Centro Avançado de Pesquisa Tecnológica do Agronegócio de Frutas - Instituto Agronômico de Campinas - 13214-820 - Jundiaí-SP. tecchio@iac.sp.gov.br. 
a irrigação pode ser utilizada com vantagens nos períodos de estiagem, como corretivo da má distribuição das chuvas e, principalmente, quando se deseja antecipação de colheita, para alcançar preços mais competitivos no mercado.

Nesse contexto, o trabalho de pesquisa teve como objetivos: avaliar a produção da figueira, alguns atributos de qualidade dos frutos e a necessidade do uso de irrigação, dentro das diferentes épocas de cultivo condicionadas pela poda, no município de Botucatu-SP.

\section{MATERIAL E MÉTODOS}

O trabalho foi conduzido em área experimental da Faculdade de Ciências Agronômicas da UNESP, Câmpus de Botucatu-SP. As coordenadas geográficas locais, de acordo com Tubelis e Salibe (1989), são: 22 52' 47" S, 48 25' 12" W e altitude de $810 \mathrm{~m}$. De acordo com Martins (2004), o clima é temperado quente (mesotérmico) com chuvas no verão e seca no inverno. A temperatura média do mês mais frio (julho) é de $17,1^{\circ} \mathrm{C}$ e a do mês mais quente (fevereiro) de $23,3{ }^{\circ} \mathrm{C}$, com precipitação média anual de $1.314 \mathrm{~mm}$. O solo da área foi classificado como Nitossolo Vermelho, segundo os critérios da Embrapa (1999).

A área total do experimento continha 420 plantas de figueira 'Roxo de Valinhos', com aproximadamente três anos de idade, dispostas em espaçamento de $3 \times 2 \mathrm{~m}$, representando uma densidade de 1.660 plantas ha $^{-1}$. O solo foi calcareado e adubado conforme resultados de análises de solo prévias e seguindo as recomendações técnicas de Campo Dall'Orto et al. (1996). Após a instalação, as plantas seguiram recebendo adubações anuais, tanto químicas como orgânicas, conforme as recomendações técnicas e uma produtividade esperada menor que $10 \mathrm{t} \mathrm{ha}^{-1}$. Os tratamentos fitossanitários e o manejo de plantas invasoras foram realizados na medida em que se fizeram necessários. As plantas foram podadas com a finalidade de adquirirem a conformação de 6 ramos produtivos, seguindo as recomendações de Rigitano ( 1964) e Penteado \& Franco (1997). Os 6 ramos foram cortados acerca de $10-15 \mathrm{~cm}$ acima da base e, em seguida, procedeu-se ao pincelamento dos cortes com pasta bordalesa. Iniciada a brotação, executaram-se desbrotas periódicas, para deixar em cada um dos três ramos adultos, apenas dois brotos vigorosos e bem distribuídos.

Os dados meteorológicos foram fornecidos pelo Departamento de Recursos Naturais da referida faculdade. O balanço hídrico da área experimental está apresentado na Figura 1, e os dados da lâmina hídrica recebida, na Tabela 1. Nos tratamentos onde estava prevista a utilização de irrigação complementar, a mesma foi realizada conforme o manejo descrito a seguir. O sistema de irrigação utilizado foi o de gotejamento localizado sob copa. A freqüência das irrigações baseou-se em dados de evaporação coletados através do Tanque Classe A, que foi instalado na área experimental. As lâminas de irrigação aplicadas corresponderam às quantidades necessárias para satisfazer $100 \%$ da evapotranspiração de referência (ETo) do tanque classe A. O momento das irrigações foi determinado em função da reposição da água evaporada no tanque.
Determinou-se a evapotranspiração de referência (ETo) por meio da seguinte equação:

Onde:

\section{ETo $=$ Kp $\times$ ECA}

ETo = evapotranspiração de referência;

$\mathrm{Kp}=$ Coeficiente do tanque classe A. Seguindo as recomendações de Hernandez (1999), adotou-se o Kp de 0,75;

$\mathrm{ECA}=$ evaporação do tanque classe A $(\mathrm{mm})$.

A determinação da evapotranspiração da cultura (Etc) foi calculada pela seguinte equação:

Onde:

Etc $=$ evapotranspiração da cultura;

$\mathrm{Kc}=$ coeficiente de cultivo. Adotou-se o Kc de 0,47, o qual foi encontrado por Olitta et al. (1979);

Eto = evapotranspiração de referência.

Foram instalados gotejadores para cada planta do experimento, e a vazão média dos mesmos foi de $2,34 \mathrm{~L} \mathrm{~h}^{-1}$. Os cálculos da necessidade de reposição de água para a cultura foram efetuados semanalmente, a partir da coleta dos dados do tanque classe A. A quantidade de água aplicada, semanalmente, foi determinada em função do balanço entre a evaporação e a precipitação do período. Detectada a necessidade de suplementação de água para a cultura, bem como a quantidade a ser aplicada, foi estabelecido o número de horas em que o equipamento deveria ficar funcionando.

Com o objetivo de avaliar os efeitos de diferentes épocas de poda, na produção e qualidade do figo 'Roxo de Valinhos', bem como os efeitos e a necessidade de irrigação, foram empregados os seguintes tratamentos: poda nos meses de julho, agosto, setembro e outubro dos anos de 2004/05 e 2005/06, com e sem o uso de irrigação complementar.

Os frutos colhidos no experimento estavam maduros, apresentavam peso médio de $45 \mathrm{a} 50 \mathrm{~g}$, porém não foram colhidos completamente graúdos e inchados, correspondentes aos normalmente vendidos no comércio de frutas ao natural, com peso médio entre 85-90 g, devido às dificuldades no manejo da área experimental. As características avaliadas foram: peso fresco médio dos frutos $(\mathrm{g})$ e produção $\left(\mathrm{g}\right.$ planta $^{-1}$ ), durante os ciclos agrícolas de 2004/05 e 2005/06. Foram avaliados alguns atributos de qualidade em pós-colheita, os quais foram realizados com os frutos no mesmo estádio de maturação, independentemente da época de poda: Sólidos solúveis - após a trituração dos frutos em processador, retirou-se uma alíquota para leitura direta dos sólidos solúveis por refratometria, em refratômetro tipo ABBE. Os resultados foram expressos em ${ }^{\circ}$ Brix. Acidez titulável - foi determinada por titulação com hidróxido de sódio $(\mathrm{NaOH}) 0,1 \mathrm{~N}$, utilizando-se de $10 \mathrm{~g}$ de polpa homogeneizada, diluídos em 100 $\mathrm{mL}$ de água destilada. O indicador utilizado foi a fenolftaleína, e os resultados foram expressos em g de ácido cítrico / $100 \mathrm{~g}$ de polpa. pH - foi determinado através do suco dos frutos homogeneizado, utilizando-se de potenciômetro da marca Digimed DMPH-2. As análises foram realizadas conforme técnicas recomendadas pelo Instituto Adolfo Lutz (1985).

$\mathrm{O}$ delineamento experimental foi o de parcelas subdivididas, com 5 repetições em blocos, onde as parcelas 
corresponderam aos tratamentos com e sem irrigação, e as subparcelas foram constituídas pelas podas. Utilizaram-se 10 plantas por parcela experimental, das quais somente as 5 centrais foram consideradas úteis (PIMENTEL GOMES, 1990).

\section{RESULTADOS E DISCUSSÃO}

Houve interação significativa entre as épocas de poda e a irrigação, para as características número e peso médio dos frutos de figueira e produção por planta, nos dois ciclos agrícolas avaliados (Tabelas 2 e 3). Na avaliação do desdobramento da interação épocas de poda e irrigação complementar, o mês de agosto (2004/05), com o uso de irrigação, foi mais favorável para a realização da poda, apresentando diferença estatística dos outros meses. Tais resultados podem ser explicados pelo maior número de brotações ocorridas nessa época de avaliação da poda.

Porém, quando se avalia o desdobramento da interação nos tratamentos sem irrigação, os resultados apresentados demonstraram não haver diferença estatística entre os meses de julho, agosto e setembro (2004/05), indicando que, na ausência de irrigação, essas três épocas são favoráveis à realização da poda, quando se avalia a característica número médio de frutos por planta. O desdobramento da interação no ciclo agrícola de 2005/06 evidenciou não haver diferenças significativas entre os meses de julho, agosto e setembro com irrigação complementar. $\mathrm{Na}$ ausência de irrigação, julho e agosto foram estatisticamente iguais.

A característica massa média dos frutos não apresentou diferença significativa com e sem o emprego de irrigação em 2004/05 e diferiu em 2005/06, onde os tratamentos com irrigação apresentaram maior massa média de frutos $(48,7 \mathrm{~g})$ em relação aos sem irrigação (46,40 g) (Tabela 3). Contudo, apesar de significativa, a diferença entre os pesos dos frutos foi muito pequena, ao contrário do que ocorreu para a variável número de frutos. O estádio de colheita dos frutos pode ter influenciado, já que a absorção de água pelo fruto, com conseqüente aumento de peso, é muito grande no final de sua formação, ou seja, imediatamente antes da maturação (PEREIRA, 1981). Se a colheita tivesse sido realizada com os figos mais inchados, talvez o efeito da irrigação sobre o peso dos frutos se tornasse maior. Em trabalhos de pesquisa já realizados, a característica mais responsiva da figueira aos tratamentos com irrigação tem sido no número de frutos.

Com relação aos meses de realização da poda, outubro (2004/05) diferiu estatisticamente dos outros meses apresentando frutos com menor massa média (39,3 g SI e 43,78 g CI), não mostrando ser uma época favorável para a realização da poda. No ciclo 2004/05 e 2005/06, as diferenças em relação ao mês de agosto foram de 8,88 e 8,34 g por fruto, o que resulta em uma considerável diminuição na produção. Devido, fundamentalmente, aos fatores climáticos e à fenologia da planta, os ramos podados no mês de outubro já apresentavam gemas intumescidas. Com a retirada desses ramos, houve esgotamento dos fotoassimilados na planta, já imobilizados nessa época de poda. Além disso, a época de maturação dos frutos provenientes dos ramos podados em outubro não apresentou condições de temperaturas necessárias para o crescimento e a maturação dos mesmos.

Os resultados de produção obtidos no primeiro ciclo de instalação do experimento em 2004/05 evidenciaram a diferença estatística superior para o uso da irrigação $\left(2.499,37 \mathrm{~g} \mathrm{planta}^{-1}\right)$ em comparação às áreas sem irrigação $\left(1.130,72 \mathrm{~g} \mathrm{planta}^{-1}\right)$. Isso representou um aumento em produção de $1.369 \mathrm{~g} \mathrm{planta}^{-1}$, correspondendo a um incremento de $56,25 \%$ nesta característica, quando são avaliados todos os meses de poda estudados. Em estudo sobre os custos e receitas provenientes do cultivo de figo para mesa, Kobayashi et al. (1993) concluíram que mesmo os custos com a irrigação serem considerados altos, ainda assim a cultura se mostrou rentável.

No desdobramento da interação entre os meses de poda, com o uso de irrigação, o mês de agosto (2004/05) foi a época mais favorável para a realização desta prática, apresentando a maior produção média do ensaio $\left(4.110,66 \mathrm{~g}\right.$ planta $\left.{ }^{1}\right)$. Em Campinas-SP, Rigitano \& Ojima (1963) concluíram que a poda efetuada em agosto proporcionou melhores resultados em comparação com a de julho, junho, maio e setembro. Também reportaram que a antecipação da poda não antecipou o ponto de colheita, não podendo ser indicada para a região de estudo.

Sem irrigação, os meses de julho, agosto e setembro (2004/ 05) foram estatisticamente semelhantes e apresentaram produções muito próximas. No ciclo agrícola de 2005/06, o mês de agosto foi estatisticamente superior a julho, setembro e outubro com irrigação, apresentando a produção de $4,11 \mathrm{~kg}$ por planta. A possibilidade de realização da poda da figueira 'Roxo de Valinhos' nestas duas épocas, para produtores que não puderem fazer uso da irrigação, mas também, permitindo com isso, um aumento no período de oferta de figos maduros no mercado (Tabela 4). Em sequeiro, julho e agosto igualaram-se estatisticamente, revelando produções de 2,17 (Julho) e 2,72 (Agosto) $\mathrm{kg}$ de figos maduros por planta.

A resposta da figueira à irrigação talvez possa ser proporcionalmente maior em relação a outras frutíferas com sistema radicular pivotante, o qual proporciona melhor captação de água pelas plantas, principalmente em profundidade. A figueira, por possuir um sistema radicular fibroso e bastante superficial, sente com muita facilidade pequenas deficiências hídricas. Para contornar esse problema, a maioria dos produtores adota o sistema de cobertura morta.

Devido ao exposto, a possível resposta de as figueiras não irrigadas apresentarem pequenas produções, principalmente no primeiro ciclo (2004/05), quando comparado com o segundo (2005/06), muito provavelmente está relacionada aos fatores climáticos, que não favoreceram um maior número de brotações e crescimento dos ramos. Porém, ao se observar a Figura 1, detectou-se um déficit hídrico acentuado nos meses de agosto e setembro de 2004, o qual não ocorreu no mesmo período em 2005. Com isso, é possível inferir que esse déficit hídrico de 60 dias, em plantas correspondentes aos tratamentos sem irrigação, fez com que as mesmas apresentassem baixa produção.

Hernandez et al. (1991) reportaram aumento de $19,4 \%$ na produção em peso dos frutos e de $14,6 \%$ no número de frutos 
por hectare, em comparação com os tratamentos sem irrigação. Da mesma maneira, Norberto et al. (2001) também reportaram incrementos em $28 \%$ no número de frutos e de $38 \%$ no comprimento de ramos com o uso da irrigação.

Alguns atributos de qualidade dos frutos, como a acidez titulável, demonstraram não haver diferença entre os meses de poda. Em média, não houve diferença entre os tratamentos avaliados no experimento para os valores de $\mathrm{pH}$ (Tabela 7). Exceção feita para a poda dos ramos de figueira efetuada no mês de outubro (2004/05) com uso de irrigação, onde os frutos

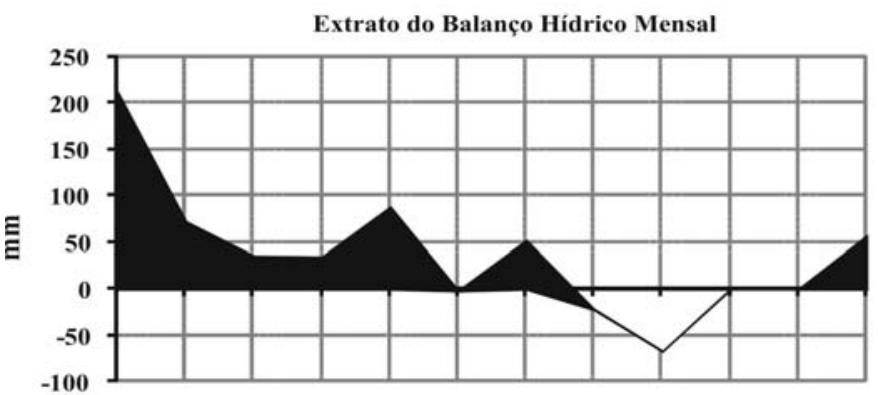

Jan Fev Mar Abr Maio Jun Jul Ago Set Out Nov Dez पDEF(-1)

FIGURA 1 - Balanço hídrico do ano de 2004. apresentaram o maior valor de pH $(5,32)$. No ciclo agrícola de 2005/06, não houve diferença significativa nos valores de $\mathrm{pH}$, sólidos solúveis e acidez titulável com relação às épocas de poda e irrigação complementar (Tabelas 5, 6 e 7).

Os resultados apresentados vêm concordar com o trabalho de Hernandez et al. (1994) e Gonçalves et al. (2006), os quais observaram que os fatores épocas de poda e sistemas de condução não influenciaram estatisticamente nas características sólidos solúveis totais, $\mathrm{pH}$, acidez titulável, açúcares totais, redutores e não redutores.

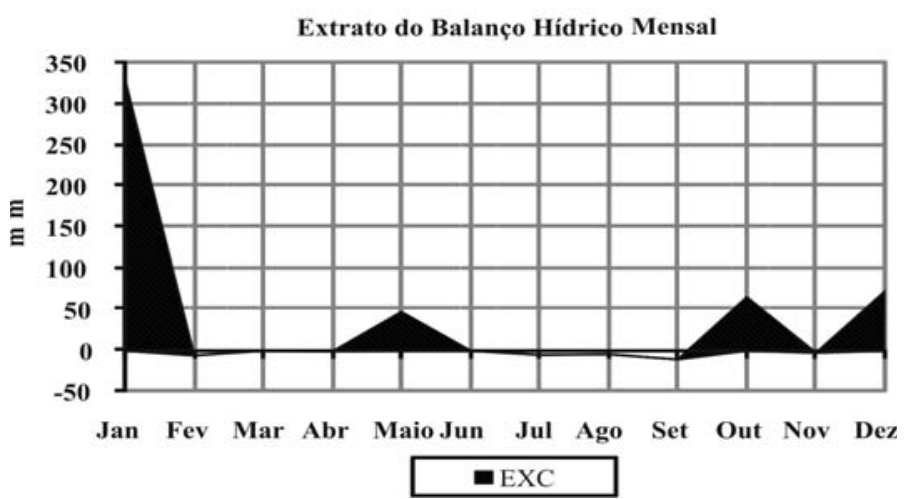

FIGURA 2 - Balanço hídrico do ano de 2005.

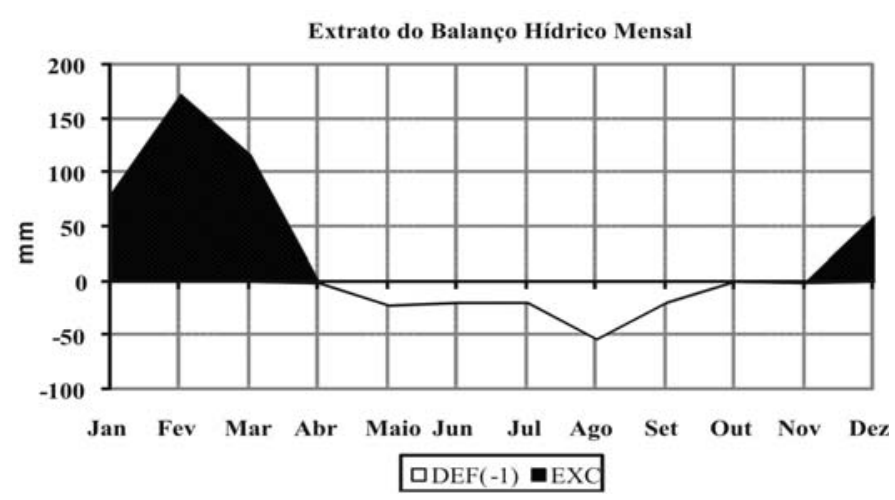

FIGURA 3 - Balanço hídrico do ano de 2006.

TABELA 1- Lâmina hídrica recebida e lâmina de irrigação aplicada (mm) nas plantas de figueira em diferentes épocas de poda e irrigação complementar. FCA/UNESP/Botucatu. 2007.

\begin{tabular}{ccccccc}
\hline CICLO & $2004 / 05$ & $2004 / 05$ & $2004 / 05$ & $2005 / 06$ & $2005 / 06$ & $2005 / 06$ \\
\hline $\begin{array}{c}\text { Épocas de poda } \\
\text { e irrigação }\end{array}$ & $\begin{array}{c}\text { Irrigação } \\
\text { efetuada no } \\
\text { período }(\mathrm{mm})\end{array}$ & $\begin{array}{c}\text { Lâmina hídrica } \\
\text { recebida }(\mathrm{mm}) \\
*\end{array}$ & $\begin{array}{c}\text { Produção }(\mathrm{g} \\
\left.\text { planta }^{-1}\right)\end{array}$ & $\begin{array}{c}\text { Irrigação } \\
\text { efetuada no } \\
\text { período }(\mathrm{mm})\end{array}$ & $\begin{array}{c}\text { Lâmina hídrica } \\
\text { recebida }(\mathrm{mm})\end{array}$ & $\begin{array}{c}\text { Produção (g } \\
\left.\text { planta }^{-1}\right)\end{array}$ \\
\hline Julho SI & - & 1004 & 1428,52 & - & 1282 & 2170,96 \\
Julho CI & 244 & $1248 * *$ & 3093,40 & 231 & $1483 * *$ & 3594,52 \\
Agosto SI & - & 1004 & 1516,42 & - & 1230 & 2272,02 \\
Agosto CI & 188 & $1192 * *$ & 3513,78 & 201 & $1431^{* *}$ & 4110,66 \\
Setemb. SI & - & 1019 & 1398,04 & - & 1181 & 1827,20 \\
Setemb. CI & 133 & $1152 * *$ & 2747,60 & 176 & $1357^{* *}$ & 3115,34 \\
Outubro SI & - & 939 & 179,90 & - & 1152 & 589,18 \\
Outubro CI & 130 & $1069 * *$ & 642,70 & 165 & $1317^{* *}$ & 951,54 \\
\hline
\end{tabular}

SI = sem irrigação. $\mathrm{CI}=$ com irrigação.

* Quantidade de água recebida pelas plantas entre a poda e a última colheita. ** Valor correspondente à soma das precipitações e das irrigações efetuadas no período. 
TABELA 2- Número médio de frutos por planta de figueira, submetida a poda e irrigação. FCA/UNESP/Botucatu. 2007.

\begin{tabular}{cccccc}
\hline \multicolumn{5}{c}{ Ciclo 2004/05 } \\
\hline Épocas & Julho & Agosto & Setembro & Outubro & Média \\
\hline Sem irrigação & $29,60 \mathrm{Ba}$ & $29,40 \mathrm{Ba}$ & $28,40 \mathrm{Ba}$ & $4,60 \mathrm{Bb}$ & $23,00 \mathrm{~B}$ \\
Com irrigação & $63,80 \mathrm{Ab}$ & $71,40 \mathrm{Aa}$ & $60,00 \mathrm{Ab}$ & $15,20 \mathrm{Ac}$ & $52,60 \mathrm{~A}$ \\
\hline Média & $46,70 \mathrm{~b}$ & $50,40 \mathrm{a}$ & $44,20 \mathrm{~b}$ & $9,90 \mathrm{c}$ & \\
\hline CV\% irrig. & \multicolumn{5}{c}{7,44} \\
\hline CV\% época & Ciclo 2005/06 & \\
\hline \multicolumn{7}{c}{6,34} \\
\hline Sem irrigação & $44,20 \mathrm{Ba}$ & $46,60 \mathrm{Ba}$ & $38,00 \mathrm{Bb}$ & $14,80 \mathrm{Bc}$ & $35,90 \mathrm{~B}$ \\
Com irrigação & $70,80 \mathrm{Aa}$ & $51,04 \mathrm{Aa}$ & $49,30 \mathrm{Aa}$ & $43,70 \mathrm{Ab}$ & $48,70 \mathrm{~A}$ \\
\hline Média & $47,48 \mathrm{a}$ & $48,82 \mathrm{a}$ & $43,65 \mathrm{~b}$ \\
\hline CV\% irrig. & \multicolumn{5}{c}{$29,25 \mathrm{c}$} \\
\hline CV\% época & \multicolumn{7}{c}{3,18} \\
\hline
\end{tabular}

Ciclo 2004/05 - D.M.S. irrigação = 2,469 D.M.S. épocas = 2,957 D.M.S. desdobramento da irrigação dentro das épocas = 3,279 D.M.S. desdobramento das épocas dentro da irrigação $=4,388$.

Ciclo 2005/06 - D.M.S. irrigação = 1,183 D.M.S. épocas = 2,620 D.M.S. desdobramento da irrigação dentro das épocas = 2,537 D.M.S. desdobramento das épocas dentro da irrigação $=3,383$.

Médias seguidas de mesma letra, maiúsculas na coluna e minúsculas na linha, não diferem entre si, pelo teste Tukey, a 5\% de probabilidade.

TABELA 3- Peso médio dos frutos (g) de plantas de figueira, submetidas a poda e irrigação. FCA/UNESP/Botucatu. 2007

\begin{tabular}{cccccr}
\hline \multicolumn{5}{c}{ Ciclo 2004/05 } \\
\hline Épocas & Julho & Agosto & Setembro & Outubro & Média \\
\hline Sem irrigação & $48,24 \mathrm{Ab}$ & $51,66 \mathrm{Aa}$ & $46,24 \mathrm{Ab}$ & $39,30 \mathrm{Bc}$ & $46,35 \mathrm{~A}$ \\
Com irrigação & $48,50 \mathrm{Aa}$ & $49,22 \mathrm{Ba}$ & $46,66 \mathrm{Aa}$ & $43,78 \mathrm{Ab}$ & $47,04 \mathrm{~A}$ \\
\hline Média & $48,37 \mathrm{~b}$ & $50,42 \mathrm{a}$ & $46,45 \mathrm{~b}$ & $41,54 \mathrm{c}$ \\
\hline CV\% irrig. & \multicolumn{5}{c}{3,55} \\
\hline CV\% época & Ciclo 2005/06 \\
\hline \multicolumn{7}{c}{4,40} \\
\hline Sem irrigação & $49,08 \mathrm{Ba}$ & $48,72 \mathrm{Ba}$ & $48,06 \mathrm{Ba}$ & $39,76 \mathrm{Bb}$ & $46,40 \mathrm{~B}$ \\
Com irrigação & $50,76 \mathrm{Aa}$ & $51,04 \mathrm{Aa}$ & $49,30 \mathrm{Ab}$ & $43,70 \mathrm{Ac}$ & $48,70 \mathrm{~A}$ \\
\hline Média & $49,92 \mathrm{a}$ & $49,88 \mathrm{a}$ & $48,68 \mathrm{~b}$ \\
\hline CV\% irrig. & \multicolumn{5}{c}{$41,54 \mathrm{c}$} \\
\hline CV\% época & \multicolumn{7}{c}{1,00} \\
\hline
\end{tabular}

Ciclo 2004/05 - D.M.S. irrigação = 1,455 D.M.S. épocas = 1,957 D.M.S. desdobramento da irrigação dentro das épocas = 2,089 D.M.S. desdobramento das épocas dentro da irrigação $=2,791$

Ciclo 2005/06 - D.M.S. irrigação = 0,418 D.M.S. épocas = 0,953 D.M.S. desdobramento da irrigação dentro das épocas = 0,920 D.M.S. desdobramento das épocas dentro da irrigação $=1,227$.

Médias seguidas de mesma letra, maiúsculas na coluna e minúsculas na linha, não diferem entre si, pelo teste Tukey, a 5\% de probabilidade.

TABELA 4- Produção média estimada $\left(\mathrm{g}_{\text {planta }}{ }^{-1}\right)$ de plantas de figueira, submetidas a poda e irrigação. FCA/UNESP/Botucatu. 2007.

\begin{tabular}{cccccc}
\hline \multicolumn{5}{c}{ Ciclo 2004/05 } \\
\hline Épocas & Julho & Agosto & Setembro & Outubro & Média \\
Sem irrigação & $1428,52 \mathrm{Ba}$ & $1516,42 \mathrm{Ba}$ & $1398,04 \mathrm{Ba}$ & $179,90 \mathrm{Bb}$ & $1130,72 \mathrm{~B}$ \\
Com irrigação & $3093,40 \mathrm{Ab}$ & $3513,78 \mathrm{Aa}$ & $2747,60 \mathrm{Ac}$ & $642,70 \mathrm{Ad}$ & $2499,37 \mathrm{~A}$ \\
\hline Média & $2260,96 \mathrm{~b}$ & $2515,10 \mathrm{a}$ & $2072,82 \mathrm{~b}$ & $411,30 \mathrm{c}$ \\
\hline \multicolumn{7}{c}{ Ciclo 2005/06 } \\
\hline CV\% irrig. & \multicolumn{5}{c}{8,19} \\
\hline CV\% época & $2170,96 \mathrm{Ba}$ & $2272,02 \mathrm{Ba}$ & $1827,20 \mathrm{Bb}$ & $589,18 \mathrm{Bc}$ & $1714,84 \mathrm{~B}$ \\
\hline Sem irrigação & $2110,66 \mathrm{Aa}$ & $3115,34 \mathrm{Ac}$ & $951,54 \mathrm{Ad}$ & $2943,01 \mathrm{~A}$ \\
Com irrigação & $3594,52 \mathrm{Ab}$ & $3191,34 \mathrm{a}$ & $2471,27 \mathrm{c}$ & $770,36 \mathrm{~d}$ & \\
\hline Média & $2882,74 \mathrm{~b}$ & 8,54 & & \\
\hline CV\% irrig. & \multicolumn{5}{c}{8,10} \\
\hline CV\% época
\end{tabular}

Ciclo 2004/05 - D.M.S. irrigação = 114,61 D.M.S. épocas $=198,85$ D.M.S. desdobramento da irrigação dentro das épocas $=199,58$ D.M.S desdobramento das épocas dentro da irrigação $=266,13$.

Ciclo 2005/06 - D.M.S. irrigação = 174,54 D.M.S. épocas = 232,72 D.M.S. desdobramento da irrigação dentro das épocas $=249,03$ D.M.S desdobramento das épocas dentro da irrigação $=332,69$.

Médias seguidas de mesma letra, maiúsculas na coluna e minúsculas na linha, não diferem entre si, pelo teste Tukey, a 5\% de probabilidade. 
TABELA 5- Acidez titulável ( $\mathrm{g}$ ácido cítrico $100 \mathrm{~g}$ de polpa $^{-1}$ ), dos frutos de plantas de figueira, submetidas a poda e irrigação. FCA/ UNESP/Botucatu. 2007.

\begin{tabular}{cccccc}
\hline \multicolumn{7}{c}{ Ciclo 2004/05 } \\
\hline Épocas & Julho & Agosto & Setembro & Outubro & Média \\
\hline Sem irrigação & $0,165 \mathrm{Aa}$ & $0,150 \mathrm{Ba}$ & $0,154 \mathrm{Ba}$ & $0,157 \mathrm{Aa}$ & $0,154 \mathrm{~B}$ \\
Com irrigação & $0,164 \mathrm{Aab}$ & $0,172 \mathrm{Aa}$ & $0,170 \mathrm{Aab}$ & $0,159 \mathrm{Ab}$ & $0,166 \mathrm{~A}$ \\
\hline Média & $0,159 \mathrm{a}$ & $0,161 \mathrm{a}$ & $0,162 \mathrm{a}$ & $0,158 \mathrm{a}$ \\
\hline CV\% irrig. & \multicolumn{7}{c}{5,53} \\
\hline CV\% época & Ciclo 2005/06 & 3,03 \\
\hline \multicolumn{7}{c}{$0,152 \mathrm{Aa}$} \\
\hline Sem irrigação & $0,158 \mathrm{Aa}$ & $0,158 \mathrm{Aa}$ & $0,142 \mathrm{Aa}$ & $0,159 \mathrm{~A}$ \\
Com irrigação & $0,194 \mathrm{Aa}$ & $0,178 \mathrm{Aa}$ & $0,158 \mathrm{Aa}$ & $0,164 \mathrm{Aa}$ & $0,166 \mathrm{~A}$ \\
\hline Média & $0,176 \mathrm{a}$ & $0,168 \mathrm{a}$ & $0,155 \mathrm{a}$ \\
\hline CV\% irrig. & \multicolumn{7}{c}{$0,153 \mathrm{a}$} \\
\hline CV\% época & \multicolumn{7}{c}{3,47} \\
\hline
\end{tabular}

Ciclo 2004/05 - D.M.S. irrigação = 0,007 D.M.S. épocas = 0,005 D.M.S. desdobramento da irrigação dentro das épocas $=0,008$ D.M.S. desdobramento das épocas dentro da irrigação $=0,011$.

Ciclo 2005/06 - D.M.S. irrigação = 0,062 D.M.S. épocas = 0,047 D.M.S. desdobramento da irrigação dentro das épocas $=0,067$ D.M.S. desdobramento das épocas dentro da irrigação $=0,022$.

Médias seguidas de mesma letra, maiúsculas na coluna e minúsculas na linha, não diferem entre si, pelo teste Tukey, a 5\% de probabilidade.

TABELA 6- Sólidos solúveis ( ${ }^{\circ}$ Brix), dos frutos de plantas de figueira, submetidas a poda e irrigação. FCA/UNESP/Botucatu. 2007.

\begin{tabular}{cccccc}
\hline \multicolumn{7}{c}{ Ciclo 2004/05 } \\
\hline Ano/2004 & Julho & Agosto & Setembro & Outubro & Média \\
Sem irrigação & $12,34 \mathrm{Aa}$ & $12,56 \mathrm{Aa}$ & $12,74 \mathrm{Aa}$ & $13,06 \mathrm{Aa}$ & $12,67 \mathrm{~A}$ \\
Com irrigação & $12,24 \mathrm{Aa}$ & $11,48 \mathrm{Ba}$ & $11,90 \mathrm{Aa}$ & $12,04 \mathrm{Ba}$ & $11,91 \mathrm{~B}$ \\
\hline Média & $12,29 \mathrm{a}$ & $12,02 \mathrm{a}$ & $12,32 \mathrm{a}$ & $12,55 \mathrm{a}$ \\
\hline CV\% irrig. & \multicolumn{5}{c}{6,96} \\
\hline CV\% época & Ciclo 2005/06 \\
\hline \multicolumn{7}{c}{4,47} \\
\hline Sem irrigação & $11,24 \mathrm{Aa}$ & $12,02 \mathrm{Aa}$ & $1158 \mathrm{Aa}$ & $11,72 \mathrm{Aa}$ & $11,64 \mathrm{~A}$ \\
Com irrigação & $11,94 \mathrm{Aa}$ & $12,18 \mathrm{Aa}$ & $11,82 \mathrm{Aa}$ & $11,36 \mathrm{Aa}$ & $11,82 \mathrm{~A}$ \\
\hline Média & $11,59 \mathrm{a}$ & $12,10 \mathrm{a}$ & $11,70 \mathrm{a}$ \\
\hline CV\% irrig. & \multicolumn{5}{c}{$11,54 \mathrm{a}$} \\
\hline CV\% época & \multicolumn{7}{c}{8,55} \\
\hline
\end{tabular}

Ciclo 2004/05 - D.M.S. irrigação = 0,751 D.M.S. épocas = 0,678 D.M.S. desdobramento da irrigação dentro das épocas $=0,858$ D.M.S. desdobramento das épocas dentro da irrigação $=1,158$

Ciclo 2005/06 - D.M.S. irrigação = 0,572 D.M.S. épocas = 1235 D.M.S. desdobramento da irrigação dentro das épocas = 1,199 D.M.S. desdobramento das épocas dentro da irrigação $=1,599$.

Médias seguidas de mesma letra, maiúsculas na coluna e minúsculas na linha, não diferem entre si, pelo teste Tukey, a 5\% de probabilidade.

TABELA 7- pH dos frutos de plantas de figueira, submetidas a poda e irrigação. FCA/UNESP/Botucatu. 2007.

\begin{tabular}{cccccc}
\hline \multicolumn{7}{c}{ Ciclo 2004/05 } \\
\hline Épocas & Julho & Agosto & Setembro & Outubro & Média \\
\hline Sem irrigação & $5,04 \mathrm{Aa}$ & $5,10 \mathrm{Aa}$ & $5,15 \mathrm{Aa}$ & $5,08 \mathrm{Ba}$ & $5,09 \mathrm{~A}$ \\
Com irrigação & $5,12 \mathrm{Aab}$ & $5,02 \mathrm{Ab}$ & $5,20 \mathrm{Aab}$ & $5,32 \mathrm{Aa}$ & $5,17 \mathrm{~A}$ \\
\hline Média & $5,08 \mathrm{a}$ & $5,06 \mathrm{a}$ & $5,18 \mathrm{a}$ & $5,20 \mathrm{a}$ & \\
\hline CV\% irrig. & \multicolumn{7}{c}{1,95} \\
\hline CV\% época & \multicolumn{7}{c}{ Ciclo 2005/06 } \\
\hline \multicolumn{7}{c}{5,77} \\
\hline Sem irrigação & $5,23 \mathrm{Aa}$ & $5,08 \mathrm{Aa}$ & $5,16 \mathrm{Aa}$ & $5,03 \mathrm{Aa}$ & $5,13 \mathrm{~A}$ \\
Com irrigação & $5,63 \mathrm{Aa}$ & $5,16 \mathrm{Aa}$ & $5,20 \mathrm{Aa}$ & $5,19 \mathrm{Aa}$ & $5,30 \mathrm{~A}$ \\
\hline Média & $5,43 \mathrm{a}$ & $5,12 \mathrm{a}$ & $5,18 \mathrm{a}$ \\
\hline CV\% irrig. & \multicolumn{5}{c}{$5,11 \mathrm{a}$} \\
\hline CV\% época & \multicolumn{7}{c}{11,32} \\
\hline
\end{tabular}

Ciclo 2004/05 - D.M.S. irrigação = 0,087 D.M.S. épocas = 0,175 D.M.S. desdobramento da irrigação dentro das épocas =0,171 D.M.S. desdobramento das épocas dentro da irrigação $=0,229$.

Ciclo 2005/06 - .M.S. irrigação = 0,369 D.M.S. épocas = 0,728 D.M.S. desdobramento da irrigação dentro das épocas = 0,716 D.M.S desdobramento das épocas dentro da irrigação $=0,954$.

Médias seguidas de mesma letra, maiúsculas na coluna e minúsculas na linha, não diferem entre si, pelo teste Tukey, a 5\% de probabilidade. 


\section{CONCLUSÕES}

1-O emprego da irrigação proporcionou produções superiores, independentemente da época de realização da poda de frutificação, quando comparada com as áreas sem irrigação.

2-A maior produtividade média do ensaio foi de 4.110,66 g planta ${ }^{-1}$ de figos maduros, resultado da poda dos 6 ramos frutíferos no final de agosto (2005/06), com o uso de irrigação.

3-Sem irrigação, a figueira pôde ser podada nos meses de julho e agosto, apresentando resultados semelhantes em produção, permitindo uma dilatação da época de poda no município de Botucatu-SP, que tradicionalmente era realizada somente no mês de julho.

\section{REFERÊNCIAS}

ALMEIDA, M.E.M. de; DE MARTIN, Z.J. de. A industrialização do figo (Ficus carica, L.). Informe Agropecuário, Belo Horizonte, v. 18, n. 188, p. 14-21, 1997.

CAMPODALL'ORTO, F.A.; CANTARELA, H.; RAIJ, B.V.; PIZA JÚNIOR, C.T. Frutas de clima temperado: II. Figo, maçã, marmelo, pêra e pêssego em pomar compacto. In: RAIJ. B.V. et al. (Ed.). Recomendações de adubação e calagem para o Estado de São Paulo. 2. ed. Campinas: Instituto Agronômico e Fundação IAC, 1996. p. 139-140.

CORRÊA, L. de S.; SANTOS, S.C. Condução e tratos culturais da figueira. In: CORRÊA, L. de S.; BOLIANI, A.C. Cultura da figueira: do plantio à comercialização. Ilha Solteira: FUNEP/ FAPESP, 1999. p. 51-68.

EMBRAPA. Centro Nacional de Pesquisa de Solos. Sistema brasileiro de classificação de solos. Rio de Janeiro, 1999. 412 p.

GONÇALVES, C.A.A.; LIMA, L.C.O.; LOPES, P.S.N.; SOUZA, M.T. Poda e sistemas de condução na produção de figos verdes. Pesquisa Agropecuária Brasileira, Brasília, v. 41, n. 6, p. $995-$ 961,2006.

HERNANDEZ, F.B.T.; CORRÊA, L. de S.; MODESTO, J.C.; YOKOTA, M.A. Efeitos de níveis de nitrogênio e da irrigação na cultura do figo. Revista Brasileira de Fruticultura, Jaboticabal, v. 13, n. 4, p. 211-216, 1991.

HERNANDEZ, F.B.T.; SUZUKI, M.A.; BUZETTI, S.; CORRÊA, L. de S. Resposta da figueira ao uso da irrigação e nitrogênio na região de Ilha Solteira. Scientia Agrícola, Piracicaba, v.51, n.1, p.99-104, 1994.
HERNANDEZ, F.B.T. Irrigação na figueira. In: CORRÊA, L.S.; BOLIANI, A.C. Cultura da figueira do plantio à comercialização. Ilha Solteira: FUNEP, 1999. p. 87-113.

INSTITUTO ADOLFO LUTZ. Normas analíticas: métodos físicos e químicos para análise de alimentos. 3. ed. São Paulo: Instituto Adolfo Lutz, 1985. 533p.

KOBAYASHI, M.K.; TARSITANO, M.A.A.; CORRÊA, L.S.; HERNANDEZ, F.B.T. Análise econômica da irrigação e adubação na cultura do figo na região de Ilha Solteira-SP. In: CONGRESSO BRASILEIRO DE ENGENHARIAAGRÍCOLA, 22., 1993, Ilhéus. Anais... v. 4, p.2435-2447.

MARTINS, D. Botucatu é realmente a cidade dos bons ares. Jornal da Faculdade de Ciências Agronômicas, Botucatu, abril, 2004.

NORBERTO, P.M.; CHALFUN, N.N.J.; PASQUAL, M.; VEIGA, R.D.; MOTA, J.H. Efeito de época de poda, cianamida hidrogenada e irrigação na produção antecipada de figos verdes. Pesquisa Agropecuária Brasileira, Brasília, v. 36, n. 11, p. 13631369, 2001.

OLITTA, A.F.L.; SAMPAIO, V.R.; BARBIN, D. Estudo da lâmina e freqüência de irrigação por gotejo na cultura do figo. O Solo, Piracicaba, v.71, n.2, p.9-22, 1979.

PENTEADO, S.R.; FRANCO, J.A.M. Figo (Fícus carica L.). Manual técnico das culturas. Campinas: SAA/CATI/DCT, 1997. p. 127-139.

PEREIRA, F.M. Cultura da figueira. Piracicaba: Livroceres, $1981.73 \mathrm{p}$.

PIMENTEL GOMES, F. Curso de estatística experimental. 13. ed. Piracicaba: Nobel, 1990. 468 p.

RIGITANO, O. Instruções para a cultura da figueira. Campinas: SAA/IAC, 1964.30p. (Boletim Técnico, 146).

RIGITANO, O.; OJIMA, M. Época de poda da figueira cultivada no Estado de São Paulo. Bragantia, Campinas, v.22, n.42, p.529$536,1963$.

TUBELIS, A.; SALIBE, A.A. Relações entre produção de laranjeira "Hamlin" e as precipitações mensais no altiplano de Botucatu. Pesquisa Agropecuária Brasileira, Brasília, v. 24, p. 801-806, 1989. 